\title{
Do parent's global rating of well-being and disease activity of children with juvenile idiopathic arthritis yield different information?
}

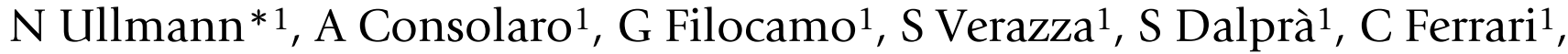 \\ R Caorsi ${ }^{1}$, S Viola ${ }^{1}$, C Visconti ${ }^{2}$, A Martini ${ }^{1}$ and A Ravelli ${ }^{1}$
}

Address: ${ }^{1}$ Istitute G. Gaslini, Genova, Italy and ${ }^{2}$ I.R.C.C.S Policlinico S. Matteo, Pavia, Italy

* Corresponding author

from I5th Paediatric Rheumatology European Society (PreS) Congress

London, UK. 14-17 September 2008

Published: 15 September 2008

Pediatric Rheumatology 2008, 6(SuppI I):PI03 doi:I0.I I86/I546-0096-6-SI-PI03

This abstract is available from: http://www.ped-rheum.com/content/6/SI/PI03

(c) 2008 Ullmann et al; licensee BioMed Central Ltd.

\section{Background}

The parents of children with juvenile idiopathic arthritis (JIA) are traditionally asked to provide a global assessment of disease status by rating the child's overall level of well-being (WB) on a 10-cm visual analogue scale (VAS). However, it has been advised that this measure does not provide a precise assessment of DA because it is largely affected by the presence of disease damage. For this reason, it has been suggested to substitute the VAS for WB with a VAS assessing specifically the level of DA.

\section{Objective}

To compare the construct validity of parent's global assessment of WB (Par WB) and parent's global assessment of DA (Par DA) in JIA.

\section{Materials and methods}

A parent of 403 JIA patients seen between 2007 and 2008 was asked to rate in 723 visits the level of child's WB and DA on two separate VAS. Construct validity of the two scales was compared by assessing their Spearman's correlation with other JIA outcome measures.

\section{Results}

Table 1 shows Spearman's correlations.

\section{Conclusion}

Par WB and Par DA were highly correlated each other and their construct validity was very similar. These findings indicate that these two measures provide the same information and can, thus, be used interchangeably.

Table I: Spearman's correlations

\begin{tabular}{llllllll}
\hline & Par WB & Par pain & JAFS & PRQL & MD global & Active joints & ESR \\
\hline Par WB & - & 0.76 & 0.59 & 0.57 & 0.52 & 0.44 & 0.33 \\
Par DA & 0.80 & 0.75 & 0.60 & 0.55 & 0.53 & 0.45 & 0.37 \\
\hline
\end{tabular}

JAFS: Juvenile Arthritis Functionality Scale; PRQL: Pediatric Rheumatology Quality of Life 